\title{
Quality of Life among Middle and Secondary School Children with Epilepsy
}

\author{
Priyanka Narayanrao Pachange ${ }^{1} \quad$ J. V. Dixit ${ }^{2} \quad$ Arjun M. C. ${ }^{3} \quad$ Akhil Dhanesh Goel $^{4}$ \\ ${ }^{1}$ Department of Community Medicine, Dr V. M. Govt. Medical \\ College, Solapur, Maharashtra, India \\ 2Department of Community Medicine, Government Medical \\ College, Aurangabad, Maharashtra, India \\ Address for correspondence Priyanka Narayanrao Pachange, \\ MBBS, MD, Department of Community Medicine, Dr V. M. \\ Govt. Medical College, Solapur, Maharashtra, 413003, India \\ (e-mail: pachangepriyankan09@gmail.com).
}

${ }^{3}$ Community Medicine \& Family Medicine, All India Institute of Medical Sciences, Bhubaneswar, Orissa, India

${ }^{4}$ Community Medicine \& Family Medicine, All India Institute of Medical Sciences, Jodhpur, Rajasthan, India

J Neurosci Rural Pract 2021;12:490-494.

\begin{abstract}
Keywords

- epilepsy

- quality of life

- QOLCE-55

- cross-sectional studies

- school children

Objectives Epilepsy is a leading cause of disability in school-going children. The objectives of this study were to estimate the prevalence of epilepsy in middle and secondary school children and to assess their quality of life (QOL).

Materials and Methods This was a cross-sectional study done in schools under the municipal corporation area of Latur Taluka, Maharashtra. At school, children were screened for epilepsy and the positive children were visited at home. Children with confirmed epilepsy were used to calculate prevalence. The QOL of children diagnosed to have epilepsy was assessed using Quality of Life in Childhood Epilepsy Questionnaire (QOLCE-55) version 1.0.

Statistical Analysis Mean scores in scales and subscales of QOLCE-55 were calculated. Association between variables was analyzed using unpaired/independent $t$-test and analysis of variance. Statistically significance was fixed for a $p$-value less than 0.05 . Results Prevalence of epilepsy in middle and secondary school children was found to be 3.20 per 1000 . In QOLCE-55, physical functioning was the most compromised, with the lowest mean QOL score (mean $=58.3$, standard deviation $=20.66$ ). Present age of the child, age at the first seizure episode, and time interval since last seizure had a statistically significant relation with QOL. The treatment gap was found to be $70.4 \%$.

Conclusions Assessment of QOL in children with epilepsy is important for effective and comprehensive management of epilepsy.
\end{abstract}

\section{Introduction}

Epilepsy is estimated to be one of the most prevalent neurological condition and a leading cause of disability in childhood. The latest global burden of disease data suggest the global prevalence to be 8.96 per 1000 in the age group less than 20 years. ${ }^{1}$ Majority of these children are from low- and

published online March 24, 2021
DOI https://doi.org/

$10.1055 / \mathrm{s}-0041-1725242$ ISSN 0976-3147. middle-income countries like India. ${ }^{2}$ The age-specific prevalence in India shows that younger age group is affected more. ${ }^{3}$

Traditionally, epilepsy management was about controlling seizure episodes and there was minimum focus on the quality of life (QOL). ${ }^{4}$ There is lack of studies on QOL among epileptic children from developing countries like India. ${ }^{4,5}$ Evidence shows that epilepsy in childhood can lead to poor psychosocial

(c) 2021. Association for Helping Neurosurgical Sick People.

This is an open access article published by Thieme under the terms of the Creative Commons Attribution-NonDerivative-NonCommercial-License, permitting copying and reproduction so long as the original work is given appropriate credit. Contents may not be used for commercial purposes, or adapted, remixed, transformed or built upon. (https://creativecommons.org/licenses/by-nc-nd/4.0/).

Thieme Medical and Scientific Publishers Pvt. Ltd. A-12, 2nd Floor, Sector 2, Noida-201301 UP, India 
outcomes. This includes anxiety and depression, ${ }^{6}$ decreased self-esteem, ${ }^{7}$ behavior issues, ${ }^{8}$ and achievements in school. ${ }^{9}$ The issues related to emotions, behavior, social competence, academic achievement, and family life can extend to adulthood..$^{10}$ Available studies from India shows that QOL are compromised in epileptic children as well as adults with epilepsy. There is also a huge treatment gap. ${ }^{3}$

$\mathrm{QOL}$ is related to the treatment gap and increased morbidity in children with epilepsy. It is pertinent that we explore this domain. The sustainable development goals 2030 can only be realized if we take a comprehensive outlook in addressing epilepsy. ${ }^{11}$ The present study aims to bridge the research gap by assessing the QOL in children of middle and secondary school children with epilepsy.

\section{Materials and Methods}

A cross-sectional study was done to estimate the prevalence and QOL of middle and secondary school going children with epilepsy. The study was conducted from December 2016 to November 2018 on children attending schools at municipal corporation area at Latur Taluka, Maharashtra. Ethics approval was obtained from Institution Ethics Committee.

\section{Inclusion Criteria}

Children diagnosed with epilepsy were included in this study.

\section{Exclusion Criteria}

Schools/parents/guardians not willing to participate were excluded

A child whose epilepsy was resolved was excluded from the study. Standard definition was used for the same.

A child who screened positive because of hypoglycemia, acute provoked seizures, febrile seizures, nonepileptic events was excluded from the study.

\section{Data Collection Procedure}

Before the start of data collection, a written permission was obtained from the education officer of municipal corporation area along with a list of all the schools in the study area. All schools in the list were visited and permission was sought from concerned authorities for conducting the study. Classes 5 to 10 were included, and each class teacher was appraised about the study. A screening questionnaire was used to find students suspected to have epilepsy. A student screened positive for more than or equal to one question was considered as a suspected case of epilepsy. To calculate prevalence, the total number of students in each class were also obtained from the school.

The parents/guardians of all suspected epileptic children were contacted through phone and consent and appointment were taken for a home visit. During the home visit, a detailed history was asked, and eligibility of the child was determined. The children included in this study were confirmed to have epilepsy by a pediatrician or neurologist. Parents were given a questionnaire that can be self-administered. The questionnaire recorded detailed sociodemographic profile and medical history of epileptic children.
Quality of Life in Childhood Epilepsy Questionnaire (QOLCE-55) version 1.0 instrument was used to assess the QOL. ${ }^{12}$ QOLCE-55 consists of four scales-cognitive, emotional, social, and physical which consist of eleven subscales-anxiety, depression, self-esteem, memory, behavior, language, attention/concentration, social activities, social interaction, physical restrictions, and other cognition. It was translated to local language Marathi. The coding of the QOLCE-55 instrument was done as per the guidelines given with the questionnaire.

\section{Statistical Analysis}

Microsoft Excel spreadsheet was used for data entry. IBM-SPSS (version 21.0) for Windows was used for data analysis. Mean scores in scales and subscales of QOLCE-55 were calculated. Statistical test of significance that includes unpaired/independent $t$-test and one-way analysis of variance was used to find the association of QOL with sociodemographic and clinical characteristics of children with epilepsy.

\section{Results}

There were 88 schools in the study area giving middle and secondary school education. Out of 88 schools, 16 denied permission to conduct the study in their school. The remaining 72 schools had 33,675 students in middle and secondary classes. Screening questionnaire was used in all these students and 316 gave one or more positive response. They were suspected to have epilepsy. The parents of these children were contacted, and home visit was made. Out of 316, there were 108 children who were confirmed to have epilepsy. - Fig. 1 shows the steps in data collection.

Prevalence of epilepsy in middle and secondary school children was found to be 3.20 per 1000 . Prevalence among male and female children in middle and secondary schools were 3.22 and 3.19 per 1000, respectively. - Table 1 shows the sociodemographic profile of epileptic children and their relationship with the overall mean QOL score. The age group 13 to 15 years had 65 (60.2\%) children compared with 35 (32.4\%) and 8 (7.4\%) in age groups 10 to 12 and 16 to 18 , respectively. The difference was statistically significant.

There were 59 (54.6\%) males and 49 (45.4\%) females. Majority of epileptic children were Hindu (68.5\%) followed by Muslim (16.7\%), Buddhist, and Jain. The literacy rate was high among parents with $77.8 \%$ mothers and $83.3 \%$ fathers being literate. The middle class $(37.0 \%)$ and lower middle class $(30.5 \%)$ family had the most number of children with epilepsy.

- Table 2 shows the clinical characteristics and their relationship with QOL. Generalized onset seizure was seen in $71.3 \%$ followed by unknown onset (14.8\%) and focal onset (13.9\%). Epileptic children having a first seizure at $>6$ months of age were $91(84.3 \%)$ and those having their last seizure $>1$ year ago were 90 (83.3\%). The difference in age at first epileptic seizure and time interval since last seizure was statistically significant.

Mean scores of all scales are given in - Table 3. Among the four scales assessed, physical functioning was most 


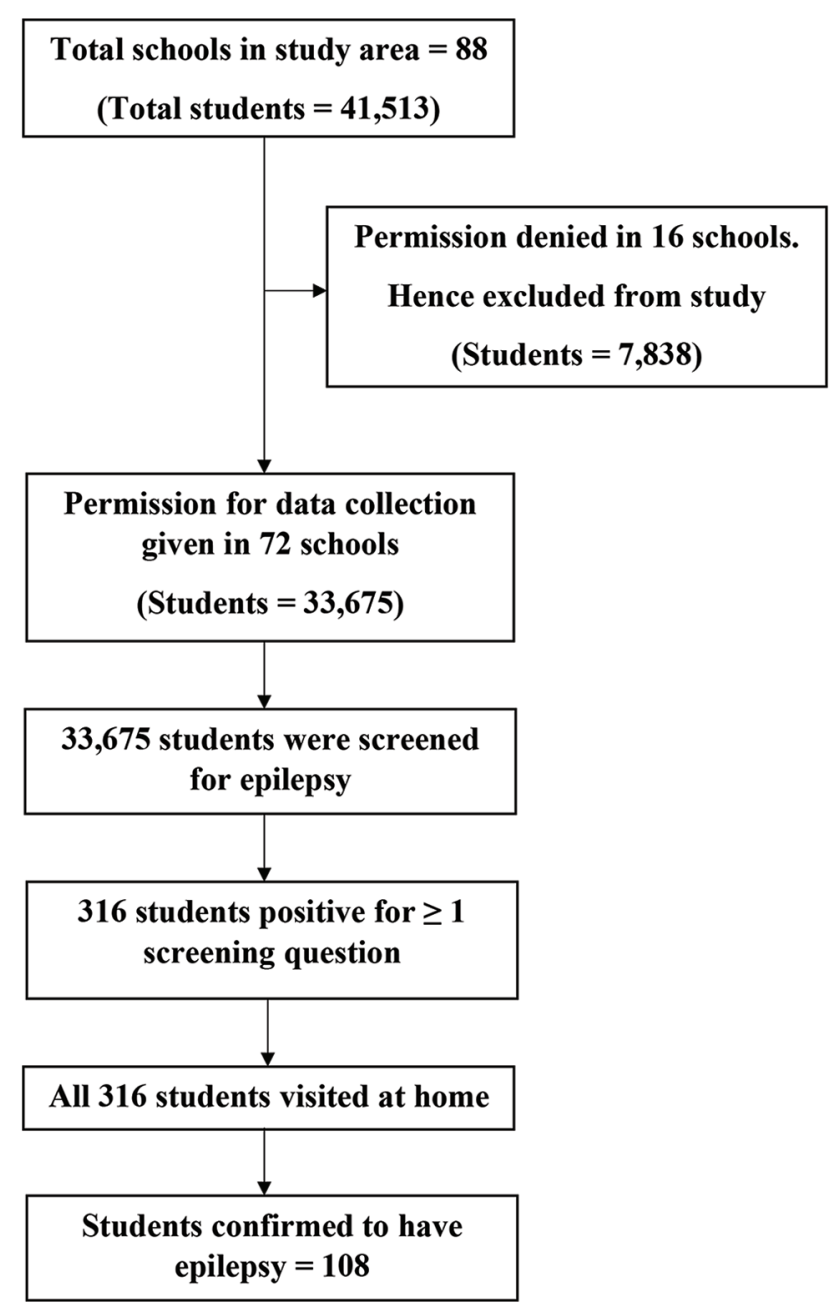

Fig. 1 Steps in data collection.

compromised with lowest mean QOL score $($ mean $=58.3$, standard deviation $[S D]=20.66$ ). . Epileptic children faced difficulty in attention/concentration ( mean $=63.2, S D=35.46$ ). There were high levels of anxiety (mean $=64.1, \mathrm{SD}=32.2$ ) and high levels of low self-esteem ( mean $=67.1, S D=29.34$ ). The least affected was social functioning (mean $=81.4, \mathrm{SD}=$ 19.37) that includes social interactions and social activities. Mean scores of all subscales are given in - Table 4 .

Out of the total 108 children confirmed to have epilepsy, $79(73.1 \%)$ had active epilepsy and 29 (26.8\%) was in remission. Appropriate treatment as per the treatment guidelines was not received by 56 (51.8\%) children with active epilepsy and 20 (18.5\%) children in remission. The treatment gap was thus found to be $70.4 \%$. The cause of such a huge treatment gap found in this study was the cost of treatment, nonavailability of drugs, lack of education, and lack of awareness about the need for regular treatment in epilepsy.

\section{Discussion}

This was a school-based cross-sectional study among students of middle and secondary classes, which measured the QOL in children with epilepsy. Prevalence of epilepsy based on this sample came to be 3.2 per 1000 , which is similar to the prevalence reported for South Asia based on global burden of disease data. ${ }^{1}$ Other notable studies from different parts of India reported a prevalence ranging from 2.0 to 6.5 per $1000 .{ }^{13,14}$

The QOL of children with epilepsy was assessed using the QOLCE-55 version 1.0 scale. This was a validated scale that can be self-administered by parents to assess the QOL in their children who is suffering from epilepsy. ${ }^{15}$ The overall mean QOL score was 69.9 $(\mathrm{SD}=13.43)$. The lowest score was seen in physical functioning subscale ( mean $=58.3, S D=20.66$ ). . The highest score was in social functioning subscale ( mean $=81.4$, SD $=19.37$ ). There were fewer studies from India that used this scale and therefore a direct comparison was not possible. A study done by Adla et $\mathrm{al}^{7}$ used QOLCE- 55 scale in a hospital-based setting and the mean overall QOL score reported was $46.8(\mathrm{SD}=10.9)$.

The factors that were significantly associated with an increased QOL score were present age of the child, age at the first onset of seizure, and time interval since last seizure. The relationship between age and QOL was found in studies done by Arya $\mathrm{V}$ et al, ${ }^{16} \mathrm{Nadkarni} J$ et al, ${ }^{4}$ Aggarwal $\mathrm{A}$ et al ${ }^{17}$ in which QOL was compromised in elder children and it was significant. This may be because when children get older, they perceive more negative aspects of life in general and develop a more negative attitude toward epilepsy.

Studies done by Adla et al, ${ }^{7}$ Arya et al, ${ }^{16}$ Nadkarni et al, ${ }^{4}$ and Aggarwal et $\mathrm{al}^{17}$ had similar findings to our study that time since last seizure was a significant factor affecting QOL. The time interval since the last seizure and QOL was related, and less time interval showed a more compromised QOL. The age of onset of seizure was associated with overall QOL score. Lower QOL score was seen in children with onset of epilepsy at age less than or equal to 6 months. In a study done by Srujana et al, ${ }^{18}$ the age at which the first seizure occurred was related to the social domain of QOL.

Education of parents, socioeconomic status, and type of seizures were not found to be a significant factor in determining the QOL in epileptic children. But similar studies from India have found that maternal education is an important factor contributing to QOL in epileptic children., ${ }^{4,7}$ Studies have shown that a strong association exists between poor socioeconomic factors and risk and outcome of epilepsy. Socioeconomic factors that increase the risk of epilepsy and its outcome include poor nutrition and hygiene, poor health seeking behavior, and infections. But there was no valid assessment of socioeconomic status with the QOL of epileptic children, even in few incidence studies. ${ }^{19}$ Association of types of seizure with QOL was also observed in few studies. ${ }^{7,18}$

There was a huge treatment gap of $70.4 \%$. Studies have shown a wide range of treatment gap in India, dependent on the study setting. ${ }^{20} \mathrm{~A}$ systematic review to estimate the prevalence of epilepsy and its patterns in India showed a treatment gap of more than $70 \%$, especially in rural areas. ${ }^{3}$ The various causes of treatment gap in this study were the cost of treatment, nonavailability of drugs in government supply, low literacy rates, and lack of awareness. High treatment gap can lead to increased disease burden. 
Table 1 Sociodemographic characteristics and relation with quality of life

\begin{tabular}{|c|c|c|c|}
\hline Sociodemographic characteristic & Number of children with epilepsy (\%) & Overall mean QOL score (SD) & $p$-Value \\
\hline \multicolumn{4}{|l|}{ Age } \\
\hline $10-12$ & $35(32.41)$ & $75.54(13.56)$ & \multirow[t]{3}{*}{0.010} \\
\hline $13-15$ & $65(60.18)$ & $67.38(12.16)$ & \\
\hline $16-18$ & $8(7.41)$ & $66.36(15.00)$ & \\
\hline \multicolumn{4}{|l|}{ Gender } \\
\hline Male & $59(54.63)$ & $71.78(13.14)$ & \multirow[t]{2}{*}{0.122} \\
\hline Female & $49(45.37)$ & $67.74(13.44)$ & \\
\hline \multicolumn{4}{|l|}{ Religion } \\
\hline Hindu & $74(68.53)$ & $70.75(13.23)$ & \multirow[t]{4}{*}{0.603} \\
\hline Muslim & $18(16.66)$ & $67.87(13.83)$ & \\
\hline Buddhist & $13(12.03)$ & $66.93(14.40)$ & \\
\hline Jain & $3(2.78)$ & 75.59 (3.95) & \\
\hline \multicolumn{4}{|l|}{ Socioeconomic status } \\
\hline Upper class & $13(12.04)$ & $71.41(10.86)$ & \multirow[t]{5}{*}{0.714} \\
\hline Upper middle class & $21(19.44)$ & $72.27(9.86)$ & \\
\hline Middle class & $40(37.04)$ & $69.01(16.84)$ & \\
\hline Lower middle class & $33(30.55)$ & $69.45(11.22)$ & \\
\hline Lower class & $1(0.93)$ & 55.63 & \\
\hline
\end{tabular}

Abbreviations: ANOVA, analysis of variance; QOL, quality of life; SD, standard deviation.

Note: $p<0.05$ is statistically significant. Test of significance: ANOVA and unpaired $t$-test.

Table 2 Clinical characteristics and relation with quality of life

\begin{tabular}{|c|c|c|c|}
\hline Clinical characteristic & Number of children with epilepsy (\%) & Overall mean QOL score (SD) & $p$-Value \\
\hline \multicolumn{4}{|l|}{ Type of seizure } \\
\hline Generalized onset & $77(71.3)$ & $69.33(13.96)$ & \multirow[t]{3}{*}{0.705} \\
\hline Focal onset & $15(13.89)$ & $72.44(12.05)$ & \\
\hline Unknown onset & $16(14.81)$ & $70.59(11.64)$ & \\
\hline \multicolumn{4}{|c|}{ Age at first epileptic seizure } \\
\hline$\leq 6 \mathrm{mo}$ & $17(15.74)$ & $59.03(18.42)$ & \multirow[t]{2}{*}{$<0.001$} \\
\hline$>6 \mathrm{mo}$ & $91(84.26)$ & $71.99(11.14)$ & \\
\hline \multicolumn{4}{|c|}{ Time interval since last seizure } \\
\hline$\leq 1 \mathrm{mo}$ & $7(6.48)$ & $50.50(18.97)$ & \multirow[t]{3}{*}{$<0.001$} \\
\hline 1 mo- 1 year & $11(10.19)$ & $76.43(7.0)$ & \\
\hline$>1$ year & $90(83.33)$ & $70.67(12.14)$ & \\
\hline
\end{tabular}

Abbreviations: ANOVA, analysis of variance; QOL, quality of life; SD, standard deviation.

Note: $p<0.05$ is statistically significant. Test of significance: ANOVA and Unpaired $t$-test.

Table 3 Mean scores of all scales of "QOLCE-55" questionnaire

\begin{tabular}{|l|l|l|l|l|}
\hline S. no. & Scale & No. of questions & Mean & SD \\
\hline 1. & Cognitive functioning & 22 & 71.59 & 18.42 \\
\hline 2. & Emotional functioning & 17 & 68.50 & 14.11 \\
\hline 3. & Social functioning & 7 & 81.41 & 19.37 \\
\hline 4. & Physical functioning & 9 & 58.29 & 20.66 \\
\hline 5. & Total QOLCE-55 score & 55 & 69.95 & 13.43 \\
\hline
\end{tabular}

Abbreviations: QOLCE-55, Quality of Life in Childhood Epilepsy Questionnaire; SD, standard deviation.

Since the study design was cross-sectional, the effect of measuring the QOL in further management of epilepsy could not be ascertained. The findings of the study can only be attributed to the school going children of middle and 
Table 4 Mean scores of all subscales of "QOLCE-55" questionnaire

\begin{tabular}{|l|l|l|}
\hline S. no. & Subscales & Mean (SD) \\
\hline 1 & Attention/concentration & $63.20(35.46)$ \\
\hline 2 & Memory & $68.29(33.69)$ \\
\hline 3 & Language & $70.08(28.35)$ \\
\hline 4 & Cognition & $68.67(25.19)$ \\
\hline 5 & Depression & $71.53(30.12)$ \\
\hline 6 & Anxiety & $64.15(32.2)$ \\
\hline 7 & Self-esteem & $67.07(29.34)$ \\
\hline 8 & Behavior & $71.64(30.16)$ \\
\hline 9 & Social interactions & $82.31(22.1)$ \\
\hline 10 & Social activities & $82.64(23.78)$ \\
\hline 11 & Physical restrictions & $58.29(20.66)$ \\
\hline
\end{tabular}

Abbreviations: QOLCE-55, Quality of Life in Childhood Epilepsy Questionnaire; SD, standard deviation.

secondary classes and may not be generalized to the entire pediatric population.

\section{Conclusion}

The overall mean QOL score based on QOLCE-55 scale is 69.9 $(\mathrm{SD}=13.43)$. Physical functioning was the most compromised domain. Age of child, age at first seizure, and time since last seizure significantly affected the QOL. Further studies are required to understand how QOL can be improved in epileptic children and their utility in personalized care and effective management of epilepsy.

\section{Ethical Approval}

The study was approved by Institutional Ethics Committee of Dr V. M. Government Medical College, Solapur, Maharashtra.

\section{Authors' Contributions}

P.N.P., J.V.D., A.M.C., and A.D.G. made substantial contributions to conception and design, acquisition of data, or analysis and interpretation of data. They contributed in drafting the article or revising it critically for important intellectual content and provided final approval of the version to be published.

\section{Funding}

None.

\section{Conflict of Interest}

None declared.

\section{References}

1 Olusanya BO, Wright SM, Nair MKC, et al; Global Research on Developmental Disabilities Collaborators (GRDDC). Global burden of childhood epilepsy, intellectual disability, and sensory impairments. Pediatrics 2020;146(1):e20192623

2 World Health Organization; The World Bank. World Report on Disability. Geneva, Switzerland: World Health Organization; 2011. Available at: www.who.int/disabilities/world report/2011/report.pdf. Accessed January 23, 2021

3 Sridharan R, Murthy BN. Prevalence and pattern of epilepsy in India. Epilepsia 1999;40(5):631-636

4 Nadkarni J, Jain A, Dwivedi R. Quality of life in children with epilepsy. Ann Indian Acad Neurol 2011;14(4):279-282

5 Malhi P, Singhi P. Correlates of quality of life with epilepsy. Indian J Pediatr 2005;72(2):131-135

6 Ettinger $A B$, Weisbrot DM, Nolan EE, et al. Symptoms of depression and anxiety in pediatric epilepsy patients. Epilepsia 1998;39(6):595-599

7 Adla N, Gade A, Puchchakayala G, et al. Assessment of Health Related Quality of Life in Children with Epilepsy Using Quality of Life in Childhood Epilepsy Questionnaire (QOLCE-55) in Tertiary Care Hospital. J Basic Clin Pharm 2017;8:74-77

8 Scott DF. Psychiatric aspects of epilepsy. $\mathrm{Br}$ J Psychiatry 1978;132:417-430

9 Sturniolo MG, Galletti F. Idiopathic epilepsy and school achievement. Arch Dis Child 1994;70(5):424-428

10 Sillanpää $M$, Jalava $M$, Kaleva $O$, Shinnar S. Long-term prognosis of seizures with onset in childhood. N Engl J Med 1998;338(24):1715-1722

11 World Health Organization. (2019). WHO /Epilepsy: a public health imperative. WHO. Available at: https://www.who.int/ mental_health/neurology/epilepsy/report_2019/en/

12 Goodwin SW, Lambrinos AI, Ferro MA, Sabaz M, Speechley KN. Development and assessment of a shortened Quality of Life in Childhood Epilepsy Questionnaire (QOLCE-55) Epilepsia 2015;56(6):864-872

13 Raina SK, Razdan S, Nanda R. Prevalence of neurological disorders in children less than 10 years of age in RS Pura town of Jammu and Kashmir. J Pediatr Neurosci 2011;6(2):103-105

14 Radhakrishnan K, Pandian JD, Santhoshkumar T, et al. Prevalence, knowledge, attitude, and practice of epilepsy in Kerala, South India. Epilepsia 2000;41(8):1027-1035

15 Puka K, Goodwin SW, Ferro MA, et al. Validation of the Quality of Life in Childhood Epilepsy Questionnaire (QOLCE-55 and QOLCE-16) for use by parents of young adults with childhood-onset epilepsy. Epilepsy Behav 2020;104(Pt A):106904

16 Arya V, Gehlawat VK, Kaushik JS, Gathwala G. Assessment of parent reported quality of life in children with epilepsy from Northern India: a cross-sectional study. J Pediatr Neurosci 2014;9(1):17-20

17 Aggarwal A, Datta V, Thakur LC. Quality of life in children with epilepsy. Indian Pediatr 2011;48(11):893-896

18 Srujana MP, Vigneshwaran E, Kumar GS, Jyoshna K, Jaffar Sadiq MM. Assessment of quality of life in children with epilepsy in rural settings of South India: a cross sectional study. CHRISMED J Health Res 2017;4:110-116

19 Amudhan S, Gururaj G, Satishchandra P. Epilepsy in India I: epidemiology and public health. Ann Indian Acad Neurol 2015;18(3):263-277

20 Bharucha NE, Bharucha EP, Bharucha AE, Bhise AV, Schoenberg BS. Prevalence of epilepsy in the Parsi community of Bombay. Epilepsia 1988;29(2):111-115 